\title{
Uma sociologia da condição proletária contemporânea
}

Ruy Braga

Introdução

0 propósito deste artigo éanalisar al gumas das principais características do trabalho dos tel eoperadores em Centrais de Teleatividades (CTAs) - os conhecidos call centers-, sujeitosàs pressões do fluxo informacional ${ }^{1}$. Paratanto, apresentaremos al guns dados col hidos na pesquisa de campo real izada com essegrupo detrabalhadores ao longo dosúltimos doisanos. Por setratar deum setor que, em certamedida, condensa uma variada gama detendências inerentesà reestruturação produtiva capitalista, a produção em escala industrial de serviçosinformacionais representa um campo privilegiado de observação das contradições eambivalências do trabal ho na contemporaneidade. Contradiçõeseambivalênciasquesetornam maissignificativasquando pensamos no processo de formação de uma condição proletária renovada pela progressiva informatização do mundo do trabalho, pela fragmentação dos coletivos detrabal hadores, pelo crescimento acel erado da oferta deempregos no setor de serviços epela superação da relação salarial "canônica".

Para tanto, pretendemosseguir al gumas das profícuas indicaçõesteóricas emetodológicas presentes no estudo realizado por StéphaneBeaud eM ichel Pialoux (1999) acerca da desestruturação do grupo operário da fábrica da Peugeot deSochaux-M ontbéliard (França), intitulado Retour sur la condition ouvrière. A pesar de se tratar de uma pesquisa etnográfica voltada para a com-

1. Preferimosempregar a expressão "CTAs" ou "Centrais deTel eatividades" a usar as expressõescorrentescall centers ou contact centers (os franceses costumam empregar a expressão centresd'appeds). Em primeiro lugar, porquereservamoso anglicismo para designar o mercado formado pelo conjunto dessas empresas. Em segundo lugar, parecenos mais afinado com o tipo deempresa em questão, poissetratadeumaformade "atividadedeprodução", e não simplesmentede "chamada" ou "contato" telefônico. 
2. De certa forma, pre tendemos seguir uma trajetória equivalente àquelatrilhada pelosautores, que, por meio da pesquisa monográfica realizada na região citada, berço histórico das fábricasPeugeot, desenvolveram diferentes pontos relacionados ao retorno dasformasdeinsegurança social - tendo àfrentea insegurançaeconômica- quecaracterizam a própria condição operária (ver também C astel, 2003).

3. D entreas quaissedestaca a descontinuidade geracional, ou seja, a interrupção dos antigos mecanismos sociais responsáveispelatransmis são, deumageração a outra, dasidéias eda visão social demundo quetradicionalmente pertenciam ao grupo operário (cf. Beaud e Pialoux, 1999, pp. 29-67, 293332). Esse aspecto da ruptura histórica compreendetanto a chegadadanovageração dejovens operários, trazida pela direçãa da Peugeot no momento em quesão introduzidas as novas formas de organização do trabalho associadasà informatização dafábrica, como a fratura ocorrida entre pais efilhos, preensão de um processo central da sociedade francesa contemporânea - a saber, a inviabilização e a desestruturação do grupo operário - , entendemos queuma parte dos problemas anal isados pelos autores não se restringe à realidadefrancesa, mas integra o quadro de uma situação social mundializada².

$\mathrm{N}$ a verdade, Beaud e Pialoux apresentam as etapas da reestruturação do processo de trabalho em um contexto marcado não apenas por profundas transformações técnico-organizacionais, mas também pela liberalização, desregulamentação, mundial ização do capital e, conseqüentemente, aumento do desemprego. Percorremos, por meio das entrevistas realizadas pelos autores, o cotidiano do grupo operário na mundialização do capital, epodemos perceber a distância que existe entre as representações difundidas, lá e aqui, pelosporta-vozes da indústriae dasfinanças, empenhadosem apresentar os operários como um grupo privilegiado por usufruir durante algum tempo decontratos detrabal ho maisou menosestáveis. Percebemostambém como osoperáriosrespondem àintensificação qual itativadosritmos produtivos eà conseqüente degradação das condições laborais, passando a conviver com o aumento do estresseno trabal ho, a precarização do emprego ea compressão salarial.

$N$ esse sentido, aceitamos a proposta mais geral do trabalho de Beaud $e$ Pialoux, que consiste em refletir a respeito das grandes rupturas e descontinuidades na história das relações de classe nosúltimos quinze anos, orquestradas à custa do grupo operário ${ }^{3}$. Ao mesmo tempo, é por avaliarmosquea grande originalidade do livro reside no enlaçamento da análise das mudanças técnico-organizacionais eeconômicas às formas de consciência políticae sindical, construídas pelos agentes para além do espaço social circunscrito pela fábrica ${ }^{4}$, que buscamos realçar a percepção dos tel eoperadores acerca dos constrangimentos impostos pelo fluxo informacional, somada às estratégias de resistência e valorização de si. Buscamos, dessa forma, associar 0 entendimento da dominação empresarial contemporânea a fenômenos assíncronos oriundos da pluralidade temporal inerente à condição proletária revivificada pela mundialização do capital ${ }^{5}$.

A verdade objetiva da exploração

$\mathrm{N}$ a verdade, como bem noslembram Beaud e Pialoux (I dem), ser operário hoje significa estar condenado a permanecer em um universo desvalorizado. E essa privação do antigo vocabulário classista traz consigo o declínio da crença na linguagem política: para um bom número de jovens, o discur- 
so do apelo à "classe" parece estar completamente ultrapassado6. N ão por outro motivo, o ponto de partida dos autores radica na constatação de que a condição operária parece ter sido abalada pela precarização de seu antigo estatuto fordista e pela freqüência com que os trabal hadores são desafiados pelo novo sistema de exploração e de dominação.

Partindo de uma questão teórica mais ampla a propósito do modo de existência e de construção do grupo operário, Beaud ePialoux desenvolvem o tema das transformações do modo de reprodução desse grupo pela emergência das lógicas de fragmentação e desestruturação de sua condição (cf. Beaud ePialoux, 2005). Conforme afórmula provocativa consagrada pel os autores, os operários "desapareceram da paisagem social": "Em suma, os operários existem, mas não os vemos mais. Por quê?" (Beaud e Pialoux, 1999, p. 15). N osúltimos quinzeanos a "questão operária" transformou-se em objeto de tal repressão que os tornou invisíveis. D e forças sociais, os operários tornaram-se objetos de compaixão ou de indiferença7.

Cabesalientar que os autorescaminharam desdeo início da pesquisa, em 1983, claramentena contracorrente dos estudos sobreo mundo do trabal ho desenvolvidos no final dos anos de 1970 edurante a década de 1980. Assim como em grande parte dos países industrializados, também na França os estudos sobreo universo produtivo estiveram profundamente marcados pelos sucessivos "adeuses ao proletariado", pela reabilitação da empresa no mundo intelectual por meio da emergência de uma dada sociologia das organizações e da empresa e pela conseqüente obsolescência do tema operário ${ }^{8}$. D e fato, não apenas falar em classe operária, mas também em classe social, tornara-se sinônimo de atrofia ou mesmo de deterioração analítica:

0 processo de reabilitação da empresa operado desdeo início dos anos de 1980 eque coincidiu estreitamentecom o "adeus ao proletariado" deváriosintelectuais "marxistas" fez com que os operários aparecessem como obstáculosà modernização da indústria, como os herdeiros deum passado revolucionário, levando necessariamentea combates deretaguarda. Progressivamente, einsensivelmente, eles deixaram o horizontemental dosformadores deopinião (intelectuais, jornalistas, políticos etc.), eisso no momento em que, em razão mesmo do enfraquecimento das formas de resistência coletiva, 0 trabalho éintensificado nas oficinas, em que as relações sociais no trabalho se deterioram, em que os operários são, por assim dizer, transformados em simples variáveis do ajuste, reduzidos a um componente da massa sal arial queépreciso comprimir sempre mais. Ao longo dosúltimos 15 anos, a "questão operária" foi verdadeiramentereprimida (Beaud ePialoux, 1999, pp. 16-17). decorrente, em grande parte, de políticas escolares vinculadas ao desmantelamento do ensino técnico-profissional. Aqui, épossível localizar uma das grandes riquezas da análise de Beaud ePialoux equeconsiste, brevemente, em estudar atrajetória dosfiIhos dos operários de Sochaux. Valenotar que este aspecto da ruptura das relações declassefoi muito menos estudado pelasociologia do traba Iho eébem menos conhecido do que aquele derivado da reestrutura ção do processo de trabalho, por exemplo.

4. Seguindo, em certa medida, uma tradição inaugurada por Engels (1988) - eretomada, entreoutros, por G ramsci (2001) - equeconsiste em privilegiar asquestões oriundas do "modo de vida" proletário, para além de um "modo de produção" simplificado pelatécnica estilizado pela economia.

5. Como a amplautilização de equipamentos "ultramodernos" (TICS) associada a formascontratuais "arcaicas" (remuneração por empreitada), ou a produção de serviços "pósmodernos" (internet, videoconfe- 
rência, data centers) re gulada por mecanismos "modernos" (tayloristas) de controlee organização do trabalho.

6. Contraditoriamente, após muitos anos de afastamento do debate público e mesmo dos trabalhos acadêmicos, 0 tema das classes sociais tem sido renovado ereval orizado por certo tipo desociologiaherderada tradição que remontaa $M$ arx (cf. Bouffartigue, 2004).

7. Segundo os autores, 0 sentimento de pertencimento de classe encontrar-seia desvalorizado, em benefício de umasociedade reduzida auma porção de indivíduos sem qualidades. 0 cres cimento do individualismo edo espírito competitivo acompanharia, conseqüentemente, a desestruturação deliberada do grupo operário.

8. Trata-sedeum tipo de abordagem queprivilegia a análise da cultura eda identidadedas empresas, fazendo emergir o sistema social constituído pelas redesformais einformaisdecolabora ção existentesentreasdiferentes forças sociais. Ver, por exemplo, Crozier eF riedberg (1977),
N esse contexto, os autores elegeram como objeto de reflexão o próprio sistema de solidariedades práticas e de defesa coletiva dos operários da Peugeot. Tal sistema configura um conjunto determinado de relações sociais essencialmente compatíveis com a exploração, pois deixa intacta a relação entreo capital eo trabal ho, não questionando a relação sal arial - ao contrário, tendendo, segundo certos parâmetros, inclusive a reforçá-la. M as, ao mesmo tempo, esse "sistema político" mostrou-se contrário ao pleno desenvolvimento da exploração, na medida em que logrou estruturar barreiras à intensificação dos ritmos eestimulou a organização de formas de resistência à supervisão, e os operários, por meio dele, puderam construir espaços de liberdade no interior da fábrica9.

0 estilo deanálise escolhido pelos autores privilegiou um tipo deestudo etnográfico centrado nas lutassimbólicas enatentativa de relacionar os diferentes domínios da existência operária: trabalho, política, família, escola, modo de vida ${ }^{10}$. Trata-se de destacar situações de exploração e dominação, bem como suas conseqüentesformas deresistência: com o tempo, novas solidariedades no trabalho emergem, afinidades simbólicas e políticas são construídasenovas militânciassurgem no chão defábrica ${ }^{11}$. 0 "apagamento" do operário configurauma "derrota simbólica" que contribui para desmobilizar o queantes costumava denominar-se "classeoperária".

Por meio das entrevistas, os autores perceberam o peso específico da perda deconfiança- não raro, traduzida em dificuldades depermanecer militando, sindical epoliticamente, no interior dafábrica- nos velhosmodelos deresistência associadosà desaparição da esperança comunista que acompanhou os eventos posteriores à queda do M uro de Berlim². U ma "derrota simbólica" que, vale lembrar, representa antes de tudo uma determinada correlação de forças sociaisamplamente desfavorável à classe operária:

Seusporta-vozes (ossindicatosoperários, os delegados defábrica, osmilitantesassociativos, o "Partido"), que tinham a vocação de osrepresentar [osoperários] no espaço público, perderam consideravelmentesua influência. A imagem queo grupo operário fazia dele próprio seencontra pálida. Estacrisederepresentação contribuiu fortementepara anãovisibilidadedo grupo. D igamosclaramente: osoperáriosforam deixando pouco a pouco de ser temidos pelos dirigentes empresariais. Trata-se de uma ruptura importante na história das relaçõesdeclasse. Elasignifica queos diques construídosao longo do tempo pelo movimento operário paraseopor à exploração, dotar o grupo deumaconsciência de classeemelhor resistir à dominação simbólica cederam amplamente. Resultado: a soberba, a arrogância eas diversas formas de desprezo dos "dominantes", por muito tempo 
bloqueadas pela existência deuma cultura política operária (institucionalizada), foram liberadasepuderam emergir sem complexos(Idem, p. 16).

N essesentido, a emergência hegemônica da categoria de "operador" aponta para uma profunda reestruturação da própria classe no período da mundialização do capital. Essa reestruturação, por sua vez, encontra-se associada a uma despolitização geral do mundo do trabalho, cujos efeitos imediatos semanifestam tanto no sentimento de abandono ede desapego à hierarquia social como na desmoralização do grupo operário. Era de esperar, pois, que a direção da Peugeot tivesse se aproveitado da oportunidade para aprofundar o processo de desestruturação do "sistema político" próprio à fábrica.

0 tema das transformações do modo de reprodução do grupo operário por meio das lógicas de fragmentação e desestruturação de sua condição no capitalismo mundializado parece-nos decisivo. Essa preocupação globalizante de Beaud e Pialoux em iluminar a desestruturação do grupo operário associada à mudança da correlação de forças estabel ecida entre as classes nos inspirou a selecionar um grupo de trabal hadores - teleoperadores-, o qual, apesar detodas as diferenças existentes com relação aos operários da Peugeot francesa, desenvolve-sedeacordo com umalógica equivalenteàquela do grupo operário deSochaux: a da despolitização das rel ações sociaisna produção e dainviabilização (nunca definitiva, valelembrar) dasformas coletivas deação social na mundialização capitalista ${ }^{13}$.

$\mathrm{N}$ a verdade, 0 crescimento das CTA sinsere-senesse período de mundialização do capital e corresponde a uma forte tendência de externalização da relação deserviço manifestada pelas empresas em todo o mundo ao longo das décadas de 1980 e 1990 (cf. Cousin, 2002; Zarifian, 2004). Trata-se deum dos principais aspectos do capitalismo mundializado: a radical alteração do meio ambienteinstitucional das empresas no sentido da emergência tendencialmente hegemônica da empresa em rede sob dominância financeira ${ }^{14}$. Sem pretender aprofundar essa indicação, é preciso dizer que as décadas de 1980 e 1990 assistiram à consolidação de um regime de acumulação sob hegemonia financeira centrado na rentabilidade dos ativos, na dominância dosfluxos informacionais ena concentração do capital financeiro em escala mundial (cf. Chesnais, 1996, 1999, 2004) ${ }^{15}$.

Contudo, foi somente na década de 1990 que tais evoluções históricas mais gerais se consolidaram, originando o fundamento capaz de estruturar um regime de acumulação mais ou menos coerente. Assistimos então à desestruturação da empresa fordista em benefício de um modelo deorgani-
Sainsaulieu (1977; 1987) e, mais recentemente, U halde(2001).

9. Contudo, a partir do início da década de 1980, cinco elementos principaisarticularam-se no sentido da destruição dessesistema político de solidariedades práticas: o rápido aumento do desemprego; aintrodução denovastecnologias deprodução e denovas formas de controlee de organização do trabalho eda produção; a utilização do discurso sobrea competitividade; a derrocadadaU nião Sovié tica; easvantagens, para a empresa, advindas do envelhecimento dos operários, seu desgaste físico emoral, após vinteanos como empregados-asentrevistas fre qüentementereferem-se a esse ponto.

10.Sob a dominação das relações de produção capitalistas, as relações entre classes sociais atravessam earticulamsecom as relações familiares, degênero, raciais, geracionaisou nacionais, sem suprimir suas especificidades. Beaud ePialoux demonstram como asidentidades excludentes, corporativistas ou comunitárias são reforçadas à medida que a 
consciênciado pertencimento a uma classe social é enfraquecida, 0 que não quer dizer de maneira alguma queas classes e suas lutas tenham desaparecido. N os paísesindustrializados, notadamente, o empre go operário não desapareceu, mas, por meio das terceirizaçōes, "deslizou" global edesgovernadamente na direção dos serviços.

11. D emaneiracorrela ta, osautoresestudam a desestabilização simbólica - categorias, hierarquias, valoreseprincípios deexistência- daantiga cultura profissional de militânciasindical epolítica. N a opinião dosautores, aatual resistência ocorreriaporméodade fesa pelo grupo de sua própria "dignidade".

12.Para além de uma simplesderrotapolítica, a desaparição da U nião Soviética transformouse em uma verdadeira derrotasimbólicavivida por um grupo operário habituado a definir partesubstantivadeseusesquemascoletivos depercepção histórica pela adesão aos princípios da Revolução deO utubro.

13. Seaidéanão consiste, demaneranenhuma, em zação das relações de produção orientado pela generalização do processo de terceirização, pela compressão dos níveis hierárquicos, pelo desenvolvimento de estratégias gerenciais objetivando a mobilização permanente da força de trabalho, pela cooperação constrangida dos assalariados, pela administração por metas, assim como pela fragmentação da relação salarial. Tratase, como bem definiu Thomas Coutrot, de uma "nova utopia capitalista": a empresa neoliberal (cf. Coutrot, 1999).

0 aumento do desemprego, por seu turno, somado à restauração das formas de competição entre os trabalhadores, associadas ao medo do desemprego, assim como a externalização das atividades de abastecimento da produção, garantiram às empresas a base instrumental para 0 aprofundamento da desestruturação dos grandes coletivos de trabalho. Por meio das terceirizações, por exemplo, logrou-se dispersar as concentrações operárias e facilitar a destruição das "antigas" relações políticas - além defazer com que os novos empregos "derrapassem" para os serviços ${ }^{16}$. D e modo equivalente, a construção de novas fábricas acentuadamente diferentes das anteriores, com uma concepção reestruturada do espaço e com fartura de equipamentos informacionais, permitiu uma profunda transformação da organização do trabal ho à qual nem todos os integrantes da "velha classe trabal hadora" puderam adaptar-se ${ }^{17}$.

A difusão das CTAs, em nossa opinião, testemunha a hegemonia desse modelo produtivo representado pela empresa neoliberal, ao mesmo tempo reticular ecentralizada pela esfera financeira. Trata-se deum tipo deempresa que tem crescido muito rapidamente na última década e despertado o interessede vários pesquisadores nas economias contemporâneas desenvolvidas. Para al guns, as CTAs correspondem a um segmento empresarial composto predominantemente por atividades de baixo valor agregado e que atraem uma força detrabal ho pouco qual ificada eformada basicamentepor estudantes. Ao mesmo tempo edemaneira contraditória, as publicações profissionais do setor situam as CT Asno prolongamento das tecnologias da informação e da comunicação (TICs) eda expansão contemporânea dosserviços- supostamenteafinadas, portanto, com a "modernidade" representada pelaeconomia informacional ${ }^{18}$.

D o ponto de vista das características gerais do trabalho dos operadores ocupados em CTAs, é possível real çar que: (a) as operações deteleatividades são realizadas 24 horas por dia, setedias por semana- conseqüentemente, as CTAs exigem uma forte disponibilidade dos trabal hadores; (b) na medida em que essa disponibilidade se encontra associada a condições difíceis de 
trabalho, temos como resultado uma forte intermitência ${ }^{19}$; (c) 0 trabalho submete-se agudamente ao fluxo informacional: ao final de uma chamada, sucede a seguinte, seja automaticamente (em interval os de 0 a 20 segundos, dependendo do tipo de operação), seja manualmente, após um máximo de dois ou três sonidos ${ }^{20}$.

Antes de avan çarmos na caracterização do trabal ho do teleoperador, cabe salientar, contudo, que a própria denominação, muito freqüente hoje em dia, de "operador", conferida aos trabal hadores em geral e aos operários em particular, aponta para um processo econômico epolítico cujo eixo consiste em dissolver a diferenciação entre trabalhadores qual ificados e não qualificados, reforçando o desaparecimento da hierarquização no interior da classe trabal hadora. D euma maneira concisa: a categoria de "operário" cede lugar à categoria homogênea e indiferenciada de "operador" - ou, no nosso caso, de "teleoperador".

A pesar das muitas diferenças, entendemos que a realidade do trabalho informacional em CTAsacompanhaa ten dênciailuminada por Beaud ePialoux de despolitização geral do mundo do trabal ho. Evidentemente, nuncaé demaisrealçar, lidamoscom uma "tendência" enão com um processo inexorável contra o qual as forças sociais em presença nada podem. M esmo que submetido ao fluxo informacional, o tel eoperador ésemprecapaz de, antagonicamente, construir espaços de liberdade no interior da produção de serviços. Evidentemente, não se trata daquela "liberdade criativa" supostamente inerenteà natureza do trabal ho informacional etão al ardeada, por exemplo, pela chamada "Escola Cognitivista" (cf. Corsani et al., 2001; G alvão et al., 2003; Lazzarato e N egri, 2001; Vercellone, 2003). Trata-se, antes, de um tipo de liberdade que se encontra circunscrita à invenção de subterfúgios objetivando escapar ao controle informático ou negociar, quando possível, restritas margens de autonomi $\mathrm{a}^{21}$. $\mathrm{N}$ o mais das vezes, o trabal ho do teleoperador é fundamentalmente regulado pela pressão do fluxo informacional, arruinado pela rotinização da comunicação e subordinado a um rígido script ${ }^{22}$, cujo objetivo central consisteem aumentar a eficácia comercial associada à redução do tempo de conexão tendo em vista a multiplicação das chamadas por horatrabal hada. Assim, a autonomia do teleoperador ésignificativamente reduzida enquanto os supervisores escutam as comunicações para assegurar o respeito ao scri pt ${ }^{23}$.

A forte taxa de enquadramento pelos supervisores (um supervisor para quinze ou vinte teleoperadores, em média) explica-se pela necessidade de controlar ao máximo os trabal hadores, impedindo que relaxem, mas sobre- "repeir" em outrocontexto 0 estudo dos autores franceses- seriaimpossível, porváriosaspectos-, nadaimpedequealgumas dasprincipaistendências identificadasporBeaude Pialoux quanto àstransformaçōesdomododere produção do grupo ope rário possam funcionar como fontedeinspiração paraaanálisedomomento brasileiro damundialização capitalista.

14. $\mathrm{N}$ aspalavras de D Urand: "As chamadastelefônicas dos clientes perturbam fortemente o trabal ho dosemprega dos e dos quadros das empresas deserviços aos particulares ou serviços públicos. Essesassalariados devem se adaptar imediatamente a uma demanda, em geral, ampliada da tarefa em curso antes deretornarem a ela, para ser perturbada novamente. Além disso, os problemas apresentados podem, na mai or partedo tempo, ser resolvidos por um pessoal menosqualificado. D eonde a diferenciação deum pessoal instalado sobreplataformastelefônicas, ca paz de responder a todas as questões a partir da identificação dos clientesedeumabasede 
dados disponível em um terminal decomputador. Rapidamentesurge a idéia de transferir este 'serviço ao cliente' para empresas subcontratadas. Ao mesmo tempo, emergem outras aplicações em massa do telefone: pesquisas por telefone, telemarketing, tratamento das chamadas vinculadasaosprogramastelevisivos- tais como: televendas, vendaspor correspondência etc." (2004, p. 232).

15. Evidentemente, essassão orientaçõesante riores às da década de 1990. É possível identificá-las, em algumame dida, tanto nacrisedo sistemamonetário instituído pelos acordos de Bretton-Woods de iníciosde1970, quanto nas tendênciasàinternacional ização das moedas e organização desistemas monetáriosdadécadade 1980 (cf. Aglietta, 1994, 1995, 1998).

16. D essa forma, emergeegeneralizaseumaes trutura deconcorrência entre osprópriostrabaIhadores, localizada predominantementeno interior da relação desubcontratação. A concorrência estruturada pelo capital entreostrabal ha dores subcontratados tudo que abandonem o fluxo informacional. Em última instância, trata-se de um tipo detrabal ho quetestemunha como nenhum outro a taylorização do trabal ho intelectual e do campo da relação de serviço: uma comunicação instrumental sob a coerção do fluxo informacional e prisioneira do script. O s objetivos são claros: multiplicar as operações e diminuir seus custos por meio da redução do estatuto da comunicação à condição de pura instrumentalidade destituída de toda significação.

Com a taylorização do campo da relação deserviço ea decorrenteautomatização do trabal ho do teleoperador, osganhos de produtividade são al cançadosà custa de um acentuado aumento da fadiga física, da postura automatizada, dos contratos de trabalho em tempo parcial, do desinteresse pela função, da vertigem oriunda da multiplicidadedaschamadas, das Lesões por Esforço R epetitivo (LERs) etc. ${ }^{24}$. Em poucas palavras: tudo parece concorrer para a degradação do campo da relação de serviço, que se vê cada dia mais desgastado pelas exigências impostas pelos ganhos de produtividade (cf. U ghetto et al., 2002).

O utra maneira de falar da degradação da relação de serviço informacional consiste em apreender o processo queimplica a transferência lenta, mas segura, de parte da carga de trabalho da CTA ao cliente. No interior do campo definido pela relação de serviço entre a empresa (ou o tel eoperador) e o cliente ou usuário, é comum que parte da carga de trabalho seja "compartilhada" entre teleoperador e cliente ${ }^{25}$. A ideologia do primado da clientela, ao que tudo indica, equivale a um eficiente instrumento de mobilização da força de trabalho:

D essaforma, épreciso constatar que o slogan segundo o qual "o clienteéo rei" não passa deuma besteira, não maistão difundida por entre os clientes, cada dia menosmistificados, mas repetida ininterruptamente por entre os assal ariados das empresas para manter ou desenvolver sua implicação no processo deracionalização da produção dos serviços. 0 qual atravessa, por sua vez, uma fase deexternalização das tarefasmaisfáceis de padronizar (centrais dechamadas, mastambém subcontratadas diversas: limpeza, manutenção, aí compreendidaa concepção rotinizada deprodutos ou desubconjuntos etc.) e, em al guns setores, pela tendência à criação de procedimentos que eliminam, pouco a pouco, o conteúdo comunicativo compreensivo que caracteriza a relação de serviço (D urand, 2004, p. 243).

A taylorização da atividade do teleoperador consiste nisto: aprisionar a força espiritual do trabalho - eseus conhecimentos práticos - em uma rotina 
produtiva marcada pela interação do trabalho com as tecnologias informacionais, assim como pela coordenação informacional entre serviços. Por meio da pressão oriunda do fluxo informacional, o trabal ho do teleoperador torna-se, finalmente, objeto de uma regulação tecnológica centralizada pelo regime de mobilização permanente da força de trabalho. A base técnica unificada proporciona a oportunidade de a empresa fixar "cientificamente" os ritmos produtivos por meio da procedimentalização e conseqüente de gradação da atividade e das condições de trabal ho do teleoperador. A intensificação dos ritmos eo aumento do controle pelos supervisores e coordenadores apenas coroam esse processo.

0 objetivo último do taylorismo na condição de modelo de organização do trabal ho ${ }^{26}$ prevalece, enfim, tendendo a submeter parte significativa do campo da relação de serviço - particularmente aquela marcada pelo deslocamento, para a periferia do sistema, das atividades consideradas de baixo valor agregado. A utilização das tecnologias informacionais no sentido do enraizamento do controle sobre o trabalhador coletivo transforma-se em um imperativo tão mais vigoroso quanto necessário para diminuir os custos empresariais. 0 trabalho subjugado pelo fluxo informacional produz uma determinada experiência classista que, de fato, atesta como nenhuma outra a taylorização dos conhecimentos originados na atividade prática do trabaIhador coletivo.

\section{A verdade subjetiva da dominação}

N ossa pesquisa de campo foi iniciada no segundo semestre de 2003 e encontra-se em curso ${ }^{27}$. Selecionamos as duas principais empresas do mercado brasileiro de call center ${ }^{28}$. Trata-se de empresas que monopolizam 0 mercado no Brasil. Para efeitosilustrativos, o número somado de funcionários das duas empresas pesquisadas - distribuídos da seguinte maneira: Empresa A, 38.000; Empresa B, 37.926 - é de 75.926. Em número de posições de atendimento (PAs), a Empresa $A$ apresenta 14.500 ea Empresa $B, 17.507$. Todas as demais treze maiores empresas do setor somadas sustentam 59.721 funcionários e 35.353 PAs. Porcentualmente, isso equivaleria a dizer que, em número total de funcionários, as empresas $A$ e $B$ somadas representam $56 \%$ do setor. Em número de PAs, as empresas $A$ e $B$ abocanham juntas $47,5 \%$ do mercado ${ }^{29}$.

D os 131 questionários respondidos pelos teleoperadores da Empresa A, $68 \%$ eram de mulheres ${ }^{30}$ e $32 \%$ de homens; quanto à idade, constatou-se não é regulada pelo salário, maspela preservação do emprego. E outrafonte deconcorrência entre os operários deveser acrescentada: a quederivado antagonis mo entreuma posição "privilegiada" própriaaos que trabal ham na empresa contratante e a posição superexplorada, como ocorrenasCTAs, dostrabalhadoresdasempresas subcontratadas.

17. A conseqüência foi umaacentuadadesvalorização práticado trabaIho: ossaláriossão individualizadosededinam re lativamente, os ritmos produtivossão intensificados, novas formas de gratificação são introduzidaseaconcorrênciaentreosoperáriosaumenta.

18. AsCTAs destacamse, também, pela capacidade de gerar empregos com relativamente poucos investimentos. Evidentemente, trata-se deumacaracterísticabastante sedutora quando consideramosasituação presente da economia brasileira.

19. A esse respeito, ver, para mais detalhes, Freire(2002).

20. Para uma caracterização muito bem realizada do teleoperador 
como "trabalhador dainformação", ver D elaunay (2003), particularmente o capítulo X.

21. Ao quetudo indica, a promessatecnicistaefetichizada de uma suposta "inserção profissional instigante" para todosos "infoinduídos" não se concretizou (cf. Grün, 2003).

22. Acercado script esua influência sobre o trabaIho dosteleoperadores, ver M ascia e Sznelwar (2000).

23.0 sinstrumentosinformacionaispermitem um acompanhamento extremamente preciso das durações das conexões, das "deslogagens" autorizadas ou não, dos atrasos no atendimento das chamadas e das pausas.

24. Sobre as LERs em CTAs, ver M arx (2000).

25. N a verdade, o cliente ajuda a co-organizar o trabalho do teleoperador e, ainda, remunera aempresaprestadora. As CTAsaumentam a pressão sobre os tel eoperadorespor meio dafilade esperadas chamadas dos clientes. O steleoperadoressão, quasesempre, em número insuficiente nas horas de pico, uma marcante presença de jovens: 43\% tinham entre 18 e 24 anos, 21\% entre 25 e 29 anos, 18\% entre 30 e 40 anos e 18\% entre 40 e 50 anos ninguém acima de 50 anos. $\mathrm{N}$ o que concerne à escolaridade, há uma forte presença de trabal hadores com o segundo grau completo, 65\%. D o restante, $29 \%$ dos entrevistados declararam estar cursando o ensino superior e $6 \%$ declararam possuir o ensino superior completo. N inguém assinalou as opções ensino primário completo ou secundário incompleto.

N o tocante ao ritmo de trabalho, as respostas indicaram uma percepção marcadamentenegativa quanto à pressão exercida pelo fluxo informacional: nada menos do que $62 \%$ dos entrevistados apontaram o comprometimento da saúde (15\%), a dificuldade dedormir, associada ao estresse decorrente da intensidade do ritmo de trabal ho (26\%), ou a dificuldade de adaptação ao ritmo (21\%); 38\% das respostas indicaram uma adaptação ao ritmo de trabalho compatível com a capacidade do tel eoperador (35\%) ou uma adaptação perfeitamente satisfatória à pressão do fluxo informacional (3\%). Aspercepções val orativas negativas - estressante e controlado (39\%), monótono e cansativo (17\% ) - somaram $56 \%$, ao passo queas respostasqueassociavam o trabal ho do teleoperador a valores positivos - criatividade e independência (9\%) , participativo e com liberdade (6\%), ecooperativo com satisfação pessoal $(26 \%)$ - totalizaram $41 \%$. A penas $3 \%$ dos entrevistados deixaram de responder.

Comparando as duas séries de respostas, é possível dizer que, grosso modo, a percepção negativa a respeito da pressão do fluxo (62\%) écorroborada pela associação do trabal ho a valores depreciativos (56\%). Correlatamente, a adaptação ao ritmo imposto pelo fluxo informacional (38\%) acompanha a atribuição de valores positivos ao trabal ho (41\%). D eforma clara, as percepções dos tel eoperadores da Empresa A encontram-se divididas, mas com uma perceptível predominância da avaliação negativa sobrea positiva. Por meio de entrevistas realizadas, é possível perceber que existe um grupo, ainda minoritário, mas expressivo, que se inclina fortemente no sentido da adaptação ao ritmo de trabalho e se sente, em alguma medida, satisfeito com o tipo de serviço que executa.

Trata-se, geralmente, de um grupo formado por trabalhadoras com idade em torno de 20 anos è̀s voltas com responsabilidades familiares urgentes: por um lado, dizem ajudar decisivamente no sustento de pais e mães; por outro, muitas delas declaram ser mães solteiras. $\mathrm{N}$ otamos que, com certa freqüência, quando as trabalhadoras declaram que os maridos estão desempregados, por exemplo, a sensação de adaptação ao fluxo ea associa- 
ção do trabal ho com valores positivos aumentam. Com base nas entrevistas, entrevemos ainda que a condição de arrimo defamília, como era de esperar, produz um efeito disciplinador muito acentuado, principal mentenos casos em que - conhecida efreqüente estratégia de recrutamento das empresasa trabalhadora declara ser mãe solteira. N essa situação, o receio de ficar desempregada aparece com muita contundência.

Possivelmenteassociado à percepção dessegrupo, 26\% das teleoperadoras entrevistadas indicaram de maneira clara quese sentiam motivadas, pretendiam seguir carreira na área eentendiam ser possível progredir profissionalmente. U m contingente expressivo (41\%) assinal ou a alternativa que classificava a profissão de teleoperador como uma "carreira de futuro, apesar dos problemas para crescer na profissão". Evidentemente, os "problemas" dizem respeito às características relativas ao tipo de meio ambienteinstitucional da empresa neoliberal, com seus níveis hierárquicos muito comprimidos. Esse elemento parece explicar, também, o contingentede $33 \%$ dos teleope radores da Empresa A que estão buscando uma alternativa ao trabalho em CTAs - 24\% declararam considerar o trabal ho "interessante", mas pretendem atuar em outra área; 3\% não a consideram uma carreira de futuro e $6 \%$ declararam não enxergar perspectiva nenhuma na profissão e apenas realizar um "bico" enquanto não conseguem outro emprego.

D equalquer maneira, $67 \%$ dos teleoperadores enxergaram um "futuro" nesse tipo de trabalho. $\mathrm{N}$ a verdade, as entrevistas indicaram que muitos deles interpretavam a profissão, a despeito dos "problemas" claramente perceptíveis para o progresso profissional, como uma espécie de "porta de entrada" para o mercado de trabalho formal e também para a aquisição de alguma qualificação técnica. N esse sentido, esse tipo de empresa em rede, regulada pelo fluxo informacional, produz um efeito ambivalente bastante curioso: por um lado, faz com que osteleoperadores compreendam quenão devem esperar pelo progresso profissional. Em termos de ascensão vertical, o que podem almejar étornar-sesupervisores ou, no máximo, monitores de qualidade. Por outro, as CTAs acenam com um "sedutor" e rápido - além de "democrático" - acesso ao emprego "estável" e ao mundo empresarial "moderno"31.

D e um ponto de vista simbólico, não deixa de ser curioso observar a equivalência entre essa "sedução" exercida pela modernidade empresarial sobre os teleoperadores e aquela oriunda do discurso gerencial da grande montadora francesa registrado por Beaud e Pialoux (1999). N este caso, os gerentes de recursos humanos aproveitaram-se amplamenteda inexperiência obrigando o cliente, não raro, a buscar um horário no qual o serviço se encontremenoscarregado. Assim, o clienteauxiliana organização ena regulação do fluxo informacional da empresa. Além disso, em alguns casos, como, por exemplo, na cidade de São Paulo, essa co-produção do serviço significa que o cliente re munera o prestador por méo datarifatelefônica.

26 Isto é, garantir à direção capitalista do processo produtivo osinstrumentosnecessáriosà apropriação dos conhecimentospráticoseà dominação do trabalhador coletivo (cf. Braverman, 1981).

27. D o ponto de vista dos passos percorridos pela pesquisa, procedemosdaseguintemaneira: 1) Visitas às empresas paraobservação diretado modo deorganização do trabalho edo processo industrial deprodução da relação deserviço; 2) realização deentrevistascom osprincipaisatores(ge rentes, coordenadoresde operações, supervisores, sindicalistaseteleoperadores) envolvidos no processo enaorganização do trabalho; 3) aplicação dequestionário entreos 
teleoperadores objetivando apreender informaçõesarespeito dosritmos de trabalho, perspectivasdecarreira, tempo derealização daope ração, relaçõesdecoope ração, atividades desupervisão, políticademe tasdasempresasetempo deintervalo paradescanso;4) real ização deentre vistasem profundidade com teleoperadores. Para umadescrição maisdetaIhada dasdatasedoslocaisdapesquisadecampo, bem como dosprocedimentosadotados, ver Braga (2006).

28. Por uma questão de economia de espaço, apresentaremos neste artigo os dados referentes a apenas uma das empresas pesquisadas (EmpresaA). Paraa aná lisedos dados daEmpre sa B, ver Braga (2006).

29. Como não poderia dexxar deser, são empresas que operam com tecnologiadeponta para o setor, além de poder contar com um diversificado lequedeclientes institucionais provenientes dos mais diferentes setores econômicos- telecomunicações, bancos, empresas deinternet, instituiç̧ões governamentais, administração pública, serviços política dos trabalhadores para conseguir dissolver os antigos coletivos de trabalho. Souberam difundir entre os novos contratados a idéia segundo a qual uma das poucas vantagens que poderiam obter trabalhando na Peugeot consistia em debutar no universo da modernidade produtiva das novas oficinas da fábrica. Para tanto, era necessário que demonstrassem ser operários eficientes, disponíveis, cooperativo $\mathrm{s}^{32}$.

Talvez a ambivalência aludida aqui - associada, obviamente, ao proble ma do desemprego - permita-nos compreender o motivo pelo qual, apesar da percepção negativa relativa ao ritmo de trabalho imposto pelo fluxo informacional e da própria associação do trabal ho a valores negativos, a concorrência para conseguir um desses empregos seja tão grande, conforme indicação das gerências de recursos humanos $(\mathrm{RH})$ das empresas pesquisadas e afirmações dos próprios teleoperadores ${ }^{33}$. $\mathrm{N}$ a verdade, é importante salientar este aspecto: os teleoperadores configuram majoritariamente uma força de trabal ho jovem, não raro disciplinada, dócil e pouco crítica. Evidentemente, essa disciplina também é forjada.

Por um lado, oscoordenadores de operaçõeseosgerentes de RH , conformepudemos verificar nas entrevistas, esforçam-se continuamente em explicar aostel eoperadoresqueeles se encontram envolvidosem uma competição econômica terrível, buscan do dissuadi-los dequal quer ação coletiva denatureza sindical ou político-organizativa. Por outro, a sel eção dos trabalhadores exigequalidades comportamentais, taiscomo disponibilidade, flexibilidade, prontidão paraaceitar novas regras, todas elas estruturadas por certainclinação em subordinar-se ao sistema. $N$ ão devemos esquecer, também, que os teleoperadores não raro são recrutados para missões provisórias e de curta duração, renovadas em função de seu comportamento no trabal ho, quando devem demonstrar disponibilidadee leal dade para com a empresa ${ }^{34}$.

Q uanto ao tempo médio necessário para a realização de cada operação, foi possível verificar que $24 \%$ dos teleoperadores consideraram esse tempo "mais do que suficiente para garantir o atendimento ao cliente com a qualidade necessária"; $27 \%$ indicaram que, apesar dos problemas considerados costumeiros, "em geral, o tempo é suficiente para atender aos clientes com qualidade"; $22 \%$ assinalaram que o tempo é suficiente apenas para "garantir 0 atendimento básico ao cliente"; $24 \%$ informaram que o tempo é "insuficiente para atender aos clientes com alguma qualidade, mesmo que básica", e 3\% não responderam. A despeito da aparenteresignação representada pelos números, nas entrevistas realizadas foi possível registrar várias menções acerca do conflito existente entre, por um lado, a pressão do fluxo 
informacional e, por outro, o desejo do teleoperador de atender ao cliente com a qualidade considerada necessária ${ }^{35}$.

0 caráter cooperativo da atividade operacional nas CTAs ocupa um espaço bastante proeminente na percepção do teleoperador a respeito de seu trabalho. E isso porque a cooperação se encontra fortemente vinculada às metas impostas externamente pelas empresas (contratante e contratada) a esses funcionários. A pesar de a natureza imanente desse trabal ho ser individual, sem o esforço combinado detodos as metas dificilmentesão al cançadas. I sso significa um comprometimento do indivíduo com a equipeeuma forte colaboração traduzida em apoio mútuo e, se possível, inexistência de faltas. Para não haver comprometimento da meta quando um teleoperador eventualmentese ausenta, os demais procuram suprir a falta do colega por meio de um reforço no ritmo do trabalho.

I sso talvez nos auxilie na compreensão do número de entrevistados que elegeu a opção "coopero com meus colegas, pois considero a cooperação essencial para alcançar as metas definidas pela empresa" (44\%). A indicação parece-nos clara: a cooperação éum instrumento para al cançar as metas impostas pelas empresas. A resposta ligada ao prazer de trabal har em equipe (41\%) também é extremamente expressiva e indica como o trabal ho do teleoperador se articula com um determinado perfil geracional da força de trabal ho: como ésabido, não é incomum que os jovens deuma maneira ge ral eo trabalhador jovem em particular experimentem certa inclinação para o trabalho em grupo, dadas suas características geracionais.

A percepção da cooperação como meio privilegiado para al cançar o objetivo definido pela empresa é reforçada, ainda, pelas respostas concernentes à política de metas: $52 \%$ dos teleoperadores assinalaram que, "desde que todos cooperem, as metas são sempre muito razoáveis". U m contingente de $15 \%$ respondeu que "geralmente as metas são razoáveis, apesar de me obrigar a um esforço enorme". 0 utros 18\% assinalaram que "raramente as metas definidas são razoáveise, normalmente, as dificuldades são enormes". As outras respostas dividiram-se entre os $6 \%$ que indicaram que, "por mais que eu me esforce, raramente consigo alcançar as metas, pois elas quase nunca são razoáveis", e os outros $6 \%$ que disseram que "as metas são sempre impossíveis de ser alcançadas, tornando o trabalho estressante e as dificuldades intransponíveis" - 3\% não responderam.

É preciso salientar quea definição das metas deve contemplar, evidentemente, chances razoáveis desucesso. C aso contrário, o fracasso contínuo produziria fatalmente uma situação de abatimento contrária ao ambiente médicos, companhiasde energia, indústrias. $0 \mathrm{~s}$ serviços oferecidos aos clientes são, em sua maioria, direcionadosa pesquisa, agendamento, cobrança evenda (tele marketing ativo); serviço de atendimento ao consumidor (SACS), agendamento, help desk, pesquisaevenda (telemarkeing receptivo), além de serviços associadosà internet, como correio eletrônico, chat, cobrowsing, videoconferência; também são oferecidos, em menor medida, serviços de banco dedados, consultoria, assinaturas.

30. Parauma instigante análise das desigualdades de gênero no setor deserviçose, mais particularmente, no setor de telecomunicações, ver G eorges (2003, 2004); sobreo mesmo tema, ver também Segnini (2001) eN ogueira (2005).

31. D efato, o "novo espírito do capitalismo" (Boltanski eC hiapello, 1999) exercealgumasedução sobreosjovensteleoperadores: entrar no mundo do trabalho informacional significa, entre outras coisas, ter perspectivas deidentificação diferentes daquelastradicionais do mo- 
vimento dos trabalhadores. M esmo quesuge rindo uma realidade viva, o termo "exploração", por exemplo, não faz partedo vocabulário desses jovens submetidos a diferentes constrangimentos simbólicosea uma sucessão de pequenas empreitadas sem futuro.

32. D essa forma, os mais jovens preocuparam-seem incorporar 0 novo vocabulário da empresa - operador, grupo etc. - eaderir ao tema da "qualidade" algo que os antigosoperários sempreserecusaram a fazer, para marcar distância da direção da empresa. N ão édeestranhar queosoperáriosda geração precedentesimplesmente não conseguissem enxergar os temporários como "verdadeiros" operários, tendo em vista o significado de luta, história comum eesperança política atribuídosà palavra (cf. Beaud e Pialoux, 1999).

33. Para mais detal hes, ver também Cousin (2002).

34. $N$ esse sentido, é possível afirmar queos teleoperadoresnão possuem uma profissão - "estimulador" necessário ao regime de mobilização permanente da força de trabalho. E a empresa procura sempred efinir a meta detal maneira quetorne possível sua consecução, mas não sem um considerável esforço por parte do funcionário ("esforço enorme"). 0 ideal é manter o teleoperador sempre tensionado no sentido deal cançar os objetivos da empresa. Além disso, cabe realçar o papel que a equipe desempenha para a atividade individual. $\mathrm{N}$ a verdade, o esforço étambém coletivo. D o grupo, o tel eoperador extrai parte damotivação paraalcançar osobjetivosimpostospelo contrato.

Por sua vez, a atividade de supervisão dividiu os teleoperadores em três blocos: um primeiro e majoritário grupo de respostas segundo o qual a liberdade de expressão é "total" (50\%); um grupo significativo para o qual existe liberdade de expressão, mesmo considerando que as opiniões "não são levadas a sério" (38\%); e finalmente um grupo minoritário de respostas (12\% ) que variam entre "ter receio de expressar as opiniões" (6\%), não ter liberdade de expressão das opiniões (3\%) e não ter "nenhuma liberdade para expor opiniões" e considerar que é "vigiado o tempo todo" (3\%). A despeito desse último bloco, é si gnificativo que a percepção dos teleoperadores da Empresa A acerca da liberdade de expressão no que concerne à atividade de supervisão seja alta (88\%). É possível que parte da explicação para esses dados se en contre nas próprias características da função do supervisor em CTAs: não raro, o supervisor é um antigo teleoperador que se destacou de alguma forma e foi promovido pela empresa ${ }^{36}$.

Por um lado, o teleoperador percebe o supervisor como uma pessoa próxima; por outro, entendeque, além de ser al guém quetambém seinteressa pelo cumprimento da meta - uma espécie de aliado - , o supervisor representa 0 principal horizonte de progressão funcional. N esse sentido, a atividade de supervisão equival ea um meio para "sair do fluxo" edesenvolver uma atividademenos desgastante. C omo o tempo médio de continuidadenafunção de teleoperador é de aproximadamente 2,5 anos, a atividade de supervisão transforma-se rapidamente em uma maneira viável de ele permanecer no universo da empresa "moderna”. M uitostel eoperadores afirmaram quea atividade de supervisão corresponde ao objetivo principal do progresso na empresa, que é citado com mais freqüência do que a mudança de função - de receptivo paraativo, por exemplo - ou deoperação, ou do que o trabal ho com a equipe dequalidade como meio principal deprogresso funcional.

$M$ as é sobretudo no que concerne ao intervalo para descansos que a insatisfação com a atividade do tel eoperador se manifesta com contundência. $\mathrm{N}$ ada menos que $88 \%$ das respostas consi deraram que o intervalo era ina- 
dequado (e 38\% dos teleoperadores assinalaram a opção "completamente insuficiente"). Sem dúvida, trata-se de uma situação crítica que articula a pressão do fluxo informacional com a falta de autonomia do teleoperador. Levando-se em conta as entrevistas realizadas posteriormente, é possível dizer que o tempo para o intervalo representa um dos pontos centrais no antagonismo inerente ao campo da taylorização da relação de serviço: por um lado, temos uma fonte de resistência do trabalhador coletivo com relação ao fluxo informacional; por outro, uma matriz permanente de críticas endereçadas à empresa.

M uitas dessas críticas apontam paraum dos problemas mais conhecidos em empresas dessa natureza: 0 assédio moral. $\mathrm{N}$ ão apenas 0 tipo ativo de assédio derivado da pressão pel os resultad os e centrado na ação coti diana de al guns supervisores e coordenadores de operação que desrespeitam os teleoperadores com gritos e insultos. 0 u mesmo 0 assédio institucionalizado e dissimulado sob a forma de "jogos" ou "brincadeiras" - o "nariz de pal haço" e a "camiseta de mico" como formas de constranger aqueles que não atingem a meta. M as muitos teleoperadores relatam um tipo "passivo" de assédio moral centrado na ausência de ação, isto é, na sistemática negativa do supervisor em autorizar a ida do teleoperador ao banheiro, ou a "deslogagem" para fumar um cigarro etc. ${ }^{37}$

$\mathrm{N}$ a verdade, pudemos verificar que, sob a forma do descontentamento com o intervalo, um tipo embrionário de resistência latente se desenvolve. M esmo que seduzi dos pela perspectiva de uma inserção formal no mercado detrabalho epor todas as promessasfeitas pelo universo empresarial "moderno", os teleoperadores repetidas vezes mencionam a "sua" dignidade individual como uma espécie de limite para a pressão da empresa por resultados. Trata-se de uma tensão importante: os teleoperadores não raro se mostram reticentes, ou atémesmo hostis, quanto àsformastradicionais deorganização coletiva, masfreqüentementerecorrem aossindicatosquando sesentem atingidos em sua dignidade pessoal.

\section{Considerações finais}

D as entrevistas realizadas é possível extrair uma compreen são mais ampla desse fenômeno: trata-se de um dos sintomas da desestruturação da antiga classe trabal hadora organizada em torno das ultrapassadas formas de composição da empresa fordista e das outrora eficazes modalidades de ação dos sindicatos. N as CTAs, os jovens trabal hadores não conseguem alcançar com sua linguagem, cultura, modosdetransmissão entre antigos e novos - associada à organização hierárquicada empresa, masuma espé ciedetrabalho pontual vinculado a uma empreitada: em geral, são contratados para um objetivo específico.

35. Apesar da natureza muito diversificada dos serviçosinformacionais oferecidospelaEmpresa A, a alusão a esse tipo deconflito foi muito freqüente. M esmo entre aqueles que jul gavam o tempo suficiente para atender 0 cliente com qualidade, foi possível identificar um grupo expressivo que considerava a "qualidade do serviço" cada vez mais ameaçada pelaspressões da empresa.

36. Trata-se, como é possível perceber, de uma experiência de liberdade vivida como "privilégio simbólico", isto é, a concessão de certa margem demanobra "expressiva" (espaços deliberdade) visando a um maior investimento no trabalho por partedo teleoperador.

37.0 descontentamento com o exíguo tempo do intervalo chega mes- 
mo ase expandir eaçambarcar o item al imentação: muitas são as críticas aos snacksvendidos pelasmáquinasautomá ticas presentes no interior da empresa. Como o período de intervalo é insuficientepara sair ese alimentar em outro lugar, muitos criticam severamente a qualidade do alimento consumido naempresa, dizendo que "as porcarias" vendidas, somadas à ansiedade inerenteao trabalho eao tempo sentado na Posição de Atendimento (PA), tornaram-se fatores deaumento da obesidade entre osteleope radores.

38. N as CTAs, éverdade, nadafavoreceaemergênciadeformasdesolidariedadesindical ou política, poisquasetudo é organizado de maneira queseimpeçaqueosteleoperadores se encontrem unscom osoutros: aspausas, por exemplo, são curtíssimaseoshorá riosdetrabal ho bastante variáveis.

39. N o final de 2005, por exemplo, ocorreu uma importante greve em umadasunidadesda Empresa A deSão PauIo, que paralisou por váriosdiasuma operação devenda do serviço de uma inserção prática nas lógicas de identificação política e simbólica da classe trabalhadora do passado e acabam sendo tragados na espiral de uma proletarização marcada por tentativas individuais deprogresso social . A própria condição de heterogeneidade vivida pelos teleoperadores - oriunda tanto da lógica da individualização, como da do salário, das metas, dos prêmios e outras - contribui para interditar a configuração de uma identidade col etiva no trabalho, de interesses comuns e do sentimento de pertencimento a um grupo sujeito às mesmas condições econômicas e políticas do restante da classe trabalhadora ${ }^{38}$.

Ao contrário, a luta pela dignidade individual parece representar o horizonte, ao menosimediato, da ação coletiva dosteleoperadores. Com isso, não queremos dizer queformas rei vindicativastradicionais, como as greves, estejam descartadas. Estas se encontram presentes e, malgrado as dificuldades aludidas anteriormente, chegam a ser freqüentes no universo do teleoperador $^{39}$. Contudo, conforme relato de sindical istas encarregados de desenvolver o trabalho de base, o acúmulo de experiência sindical é muito lento e o trabal ho organizativo realizado pel ossindicatosérepetidamenteperdido em razão da elevada rotatividade.

D essa forma, a lógica da individual ização da ação inerenteà estrutura da empresa em rede e financei rizada predomina sobre a lógica da ação coletiva inerente ao sindicalismo. A condição fragmentária da inserção do teleoperador no trabalho produz um efeito assíncrono: a multiplicidade de temporalidades, derivada do labor cotidiano, "bloqueia" severamente a ação propriamentecoletiva. Q uando uma seqüência de PAsinterrompe sua atividade em protesto, outras seqüências continuam trabalhando; quando toda uma operação é paralisada, outras operações permanecem ativas... E as lutas mais ou menos vinculadas ao reconhecimento da dignidade individual - contra o assédio moral, pelo direito de ir ao banheiro, pela ampliação dos intervalos, pela melhoria dos lanches etc. - acomodam-se no espaço outrora reservado às lutas salariais do conjunto da categoria ${ }^{40}$.

Bourdieu auxilia-nos a compreender melhor esse ponto:

$\mathrm{N}$ as situações detrabal ho mais constrangedoras, como o trabal ho em linha demontagem, o investimento no trabal ho tende a variar na razão inversa à coerção externa no trabal ho. Por conseguinte, em diversas situações de trabal ho, a margem de liberdade deixada ao trabalhador (a parcel a de incerteza na definição das tarefas, que abreuma possibilidadedejogo) constitui um móvel central: ela introduz o risco do não-trabal ho ou mesmo de sabotagem, de depredação etc.; mas ela abrea possi bilidade do investi- 
mento no trabalho eda auto-exploração. 0 quedepende, em amplamedida, da maneira como épercebida, apreciadae compreendida (logo, dos esquemas de percepção e, em particular, dastradiç̧ões profissionaisesindicais, etambém da memória das condiç̧ões nas quais el a foi adquirida ou conquistada, eda situação anterior). Paradoxalmente, é porqueelaépercebida como uma conquista (por exemplo, a liberdade defumar um cigarro, desedeslocar etc.) ou mesmo um privilégio (concedido aosmais antigosou aos maisqualificados) queelapode contribuir para mascarar a coerção global queconfere todo valor àliberdade (2001, p. 249).

Referências Bibliográficas

Aglietta, M . (org.). (1994), CinquenteansaprésB retton Woods. Paris, Econômica. . (1995), M acroéconomiefinancière. Paris, La D écouverte. . (1998), M acroéconomie financière2. Paris, La D écouverte.

Aglietta, M . \& Brender, A. (1984), Lesméamorphosesdela sociééésalariale la Franceem proje. Paris, Clamann-Levy.

Beaud, S. \& Pialoux, M . (1999), Retour sur la condition ouvrière: enquête aux usines Peugeot deSochaux-M ontbéliard. Paris, Fayard.

. (2001), "Unesociologiedela condition ouvrièreaujourd'hui". Contretemps, Paris, 1. . (2005), "Etnografia operária e sociologia: a composição de uma equipe". In:

Encrevé, P. \& Lagrave, R.-M . Trabalhar com Bourdieu. São Paulo, Bertrand Brasil.

Boltanski, L. \& Chiapello, E. (1999), Lenouvel esprit du capitalisme. Paris, Gallimard.

Bouffartigue, P. (org.). (2004), Leretour desclassessociales. Paris, La Dispute.

Bourdieu, P. (2001), M editaçōespascalianas. São Paulo, Bertrand Brasil.

Braga, R. (2006), "N ossa herança (info)taylorista: aspectos da degradação do trabalho e da relação de serviço em centrais de teleatividades". Revista Brasileira de Saúde 0 cupacional, São Paulo (no prelo).

Braverm An, H . (1981), Trabalho ecapital monopoli sta: a degradação do trabal ho no século $X X$. Rio deJaneiro, JorgeZahar.

CASTEL, R. (2003), L'insecuritésociale: qu'est-cequ'êtreprotégé? Paris, Éditions du Seuil/La Republiquedês Idées

Ch ESNAIS, F. (1996), A mundialização do capital. São Paulo, Xamã.

(org.). (1999), A mundialização financei ra: gênese, custose riscos. São Paulo, Xamã. (org.). (2004), La finance mondialiséé racines sociales et politiques, configuration, conséquences Paris, LaD écouverte.

Corsani, A.; D ieuaide, P. \& Azaīs, C. (orgs.). (2001), Versun capitalisme cognitif: entre mutation du travail et territoires. Paris, L'H armattan. conexão deinternet por banda larga.

40.N ovamente, não deixa de ser interessantesalientar o paralelismo existenteentreessequadro de "bloqueio dapercepção propriamente política do grupo" eum dos aspectos notados por Beaud e Pialoux acerca da crise do militantismo operário após a derrocada das socieda dessubmetidas pelo stalinismo: "Ao longo dessesúltimos 15 anosfoi a própria idéia de um avanço coletivo do grupo operário quese perdeu. Com ela desapareceu a esperança política de uma tran sformação radical das relações sociais sobrea base deum modelo detipo socialista. A confusão específicados militantesoperários residetal vez na extrema dificuldade que eles constatam em pensar sua condição eaquela deseu grupo em termos 'políticos' como havia acontecido em toda a história do movimento operário francês. $\mathrm{H}$ oje, cada um define por si mesmo 'suas' maneiras de defender 'sua' dignidade [...]" (1999, p. 364). 
Cousin , O . (2002), "Les ambivalences du travail: les salariés peu qualifiés dansles centres d'appels". Sociologiedu Travail, 44, Paris.

Coutrot, T. (1999), L'entrepriseneo-libérale, nouvelleutopiecapitaliste? Paris, La D écouverte.

Crozier, M . \& Friedberg, E. (1977), L'acteur et lesystème. Paris, LeSeuil.

D elaunay, Q . (2003), “Uneenquêtedanslescentresd'appelsen France(2001)”. In: LeChat, N .\& D elaunay, J.-C. (2003), Les centres d'appels: un secteur en clair-obscur. Paris, L'H armattan.

D URAND, J.-P. (2004), La chaîneinvisible: travailler aujourd'hui: flux tendu et servitude volontaire. Paris, Seuil.

En GeLs, F. (1988), Situação da classe trabalhadora na Inglaterra. São Paulo, G lobal.

Freire, O . N . (2002), "Ser atendentea vida toda éhumanamente impossível": serviço de teleatendimento ecusto humano do trabalho. Braślia. D issertação demestrado em Psicologia. U niversidade de Brasília.

Galvão, A.; SILva, G . \& Cocco, G. (orgs.). (2003), Capitalismo cognitivo: trabalho, redes einovação. Rio deJaneiro, DP\&A.

Georges, I. (2003), "Trabal ho eemprego: C arreirasformaisetrajetórias socioprofissionais demulheres no setor terciário brasileiro". D ocumento detrabalho. São Paulo, C ebrap. . (2004), "O s empregos subalternos no setor de telecomunicações: comparações França-Alemanha". EstudosFeministas, 2 (12), Florianópolis.

Gram scl, A. (2001), Cadernosdo cárcere (vol. 4). São Paulo, Civilização Brasileira.

G rün , R. (2003), “A promessa da 'inserção profissional instigante' da sociedadeem rede: A imposição de sentido esua sociologia". D ados, 46 (1).

Lazzarato, M .\& N egri, A. (2001), Trabalho imaterial. Rio de Janeiro, D P\&A.

Lechat, N . \& D elaunay, J.-C. (2003), Lescentresd'appels, un secteur en dair-obscur. Paris, L'H armattan.

M ARX, R. (2000), "LER eorganização do trabal ho no setor de serviços: o caso de call centers em atendimento deserviçosfinanceiros". In: Szn ELWAR, L. I. \& ZIDAN, L. N . (2000), 0 trabalho humano com sistemasinformatizadosno setor deserviços. São Paulo, Plêiade.

M ascia, F. L. \& Sznelwar, L. I. (2000), “D iálogo e constrangimentos do script na atividade deatendimento a clientes". In: Szn ELWAR, L. I. \& ZIDAN, L. N . (2000), 0 trabalho humano com sistemasinformatizadosno setor deserviços. São Paulo, Plêiade.

N O GUEIRA, C. M . (2005), 0 trabalho duplicado: a divisão sexual no trabalho ena reprodução: um estudo dasmulherestrabalhadorasno telemarketing. São Paulo, Tese dedoutora do em Serviço Social. Pontifícia U niversidadeC atólica deSão Paulo.

Sain SAulieu, R. (1977), L'identitéau travail: les effetsculturelsdel'organization. Paris, Presses deSciencesPó.

. (1987), Sociologie del'organisation et del'entreprise. Paris, Presses deSciences Pó. 
SegninI, L. (2001), "Relações de gênero eracionalização do trabalho em serviços deatendimento a distância”. I n: SALERn O, M . S. (org.). (2001), Relação deserviço: produção e avaliação. São Paulo, Senac.

U ghetto, P.; Besucco, N .; T allard, M . \& Tertre, C. (2002), "La relation deservice: unetension versun nouveau modéle detravail?". Revuedel'IRES, 39.

U HALDE, M . (org.). (2001), L'intervention sociologiqueen entreprises dela criseà la régulation sociale. Paris, D esclée de Brouwer.

Vercellone, C. (org.). (2003), Sommes-noussortisdu capitalismeindustrie? Paris, LaD ispute. ZaRIFIAN, P. (2004), "Le travail dans un centre d'appel", http://perso.wanadoo.fr/ philippe.zarifian/page33.htm, consultado em nov. 2004.

\section{Resumo}

Uma sociologia da condição proletária contemporânea

Com o incremento do processo deterceirização experimentado pelas empresas ao longo das duasúltimas décadas, um novo tipo detrabalhador desenvolveu-sena periferia do sistema produtivo: o tel eoperador. Responsável por um contingente diversificado deatividades informacionais, o trabalho do teleoperador despertou, pelaforça de seu sólido crescimento numérico, o interesse de vários pesquisadores em diferentesáreas do conhecimento. Por meio da análise do trabalho do teleoperador, o propósito desteartigo écontribuir parauma reflexão acerca da renovação da própria condição proletária contemporânea. Ao contrário do que muitos previam há quinzeanos, a revolução informacional não foi capaz desuperar a oposição existenteentreas atividades laborai sdeexecução eas de concepção: serviu, antes, como um privilegiado instrumento de controle e de rotinização da força espiritual do trabalho. Para tanto, pretendemos seguir al gumas indicações sobre a condição operária contemporânea presentes no inspirador estudo deStéphane Beaud eM ichel Pialoux acerca da montadora Peugeot de Sochaux-M ontbéliard.

Palavras-chave: Trabalho informacional; C ondição proletária; Teleoperadores; Classes sociais.

\section{Abstract}

A sociology of the contemporary working class

Theincreasein company outsourcing over thelast two decades has led to the development of a new type of worker on the margins of the productivesystem: the call centreoperator. Responsiblefor a widerange of information services, therapid expansion in call centres has stirred theinterest of a number of researchers in different areas of knowledge. Analyzing the work of the call centre operator, the articlelooksto deepen our comprehension of the sea-change currently affecting today's working class. In contrast to what many forecasted somefifteen years ago, the information revolution has failed to dissolve the opposition 
between manual and mental work activities: instead, it has served as akey instrument for controlling and routinizing intellectual work. In turning to thistheme, weexploresomeof the insights into the contemporary working class condition found in the inspirational study by Stéphane Beaud and M ichel Pialoux on the Peugeot car assembly plant in Sochaux-M ontbéliard.

Keywords: Information services; Proletarian condition; C all centreoperators; Social classes.

Texto recebido e aprovado em 15/2/2006.

Ruy Braga é professor do D epartamento deSociologia daU SP eautor deA nostalgia do fordis mo (São Paulo, Xamã, 2003). Colaboraram os bolsistas do programa PIBIC-CN Pq Gabriel FreitasC asoni eN atália Padovani. E-mail: ruy. braga@uol.com.br 